\title{
Evolution of a cycloaddition-rearrangement approach to the squalestatins: a quarter-century odyssey
}

\section{Hasanain A. A. Almohseni}

David M. Hodgson*

Department of Chemistry, Chemistry Research Laboratory

University of Oxford, Mansfield Road, Oxford OX1 3TA, UK

david.hodgson@chem.ox.ac.uk

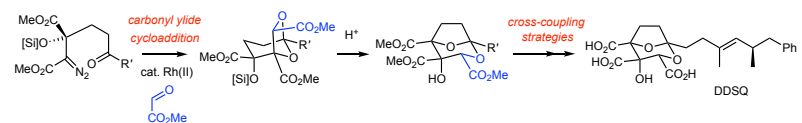

\begin{tabular}{|c|c|}
\hline \multicolumn{2}{|c|}{$\begin{array}{l}\text { Reccived: } \\
\text { Accepted: } \\
\text { Published online: } \\
\text { Dol: }\end{array}$} \\
\hline \multicolumn{2}{|c|}{$\begin{array}{l}\text { Abstract The highs, lows and diversions of a journey leading to two } \\
\text { syntheses of } 6,7 \text {-dideoxysqualestatin } \mathrm{H} 5 \text { is described. Both syntheses relied } \\
\text { on highly diastereoselective } n \text {-alkylations of a tartrate acetonide enolate } \\
\text { and subsequent oxidation-hydrolysis to provide an asymmetric entry to } \beta \text { - } \\
\text { hydroxy- } \alpha \text {-ketoester motifs. The latter were differentially elaborated to } \\
\text { diazoketones which underwent stereo- and regioselective Rh(II)-catalysed } \\
\text { cyclic carbonyl ylide formation-cycloaddition and then acid-catalysed } \\
\text { transketalisation to generate the } 2,8 \text {-dioxabicyclo[3.2.1]octane core of the } \\
\text { squalestatins/zaragozic acids at the correct tricarboxylate oxidation level. } \\
\text { The unsaturated side-chain was either protected with a bromide substituent } \\
\text { during the transketalisation, or introduced afterwards by a stereoretentive }\end{array}$} \\
\hline Ni-cata & ed $\mathrm{Csp}^{3}-\mathrm{Csp}^{2}$ cross-electrophile coupling. \\
\hline & Introduction \\
\hline & Racemic Model Studies to the Squalestatin/Zaragozic Acid Core \\
\hline & Asymmetric Model Studies to a Keto $\alpha$-Diazoester \\
\hline & Dialkyl Squarate Desymmetrisation \\
\hline & Tartrate Alkylation \\
\hline 3.2 .1 & $\begin{array}{l}\text { Further Studies on Seebach's Alkylation Chemistry } \\
\text {. }\end{array}$ \\
\hline & Failure at the Penultimate Step to DDSQ \\
\hline 5 & $\begin{array}{l}\text { Second-Generation Approach to DDSQ: a Bromide Substituent } \\
\text { Strategy }\end{array}$ \\
\hline 5.1 & $\begin{array}{l}\text { Stereoselective Routes to E-Alkenyl Halides via } \beta \text {-Oxido } \\
\text { Phosphonium Ylides }\end{array}$ \\
\hline 5.2 & Back to DDSQ synthesis \\
\hline & An Alternative Strategy to DDSQ: by Cross-Electrophile Coupling \\
\hline 7 & $\begin{array}{l}\text { Alkene Ozonolysis in the Presence of Diazo Functionality: } \\
\text { Accessing } \alpha \text {-Ketoester Intermediates }\end{array}$ \\
\hline 8 & Summary \\
\hline
\end{tabular}

\section{Introduction}

Following Peter Vollhardt's invitation to contribute an Encore Account to our 2006 essay on lithiated epoxides and aziridines ${ }^{2}$ and his reassurances against the principal author's (DMH's) wariness of stepping in the same river twice, the following provides an overview of our synthetic studies to the squalestatins. Once again an attempt has been made to keep the tone of this article in line with the original aims of these Accounts. ${ }^{3}$ Like the lithiated epoxide research programme our squalestatin studies, although only recently completed, can also be traced back to the start of DMH's independent academic career at the University of Reading in 1990. At that time, occasional departmental trips would be arranged to see prominent external speakers visiting the Dyson Perrins Laboratory in nearby Oxford. The first of these DMH attended in October 1990 was given by Al Padwa, whose emerging studies with diazo carbonyl compounds in Rh(II)-catalysed tandem carbonyl ylide formation-1,3-dipolar cycloadditions ${ }^{4}$ left a lasting impression of the potential power of this transformation to rapidly generate molecular complexity.

The triacid 1 (Figure 1) was independently reported in the mainstream literature by Glaxo and Merck groups in 1992 and assigned the names squalestatin $\mathrm{S}^{5}$ and zaragozic acid A (ZAA), ${ }^{6}$ respectively. It was discovered during screening programmes of fungal metabolites to find inhibitors of specific enzymatic steps in the synthesis of cholesterol. The triacid $\mathbf{1}$ was the first natural product found to be a potent inhibitor of squalene synthase and it also exhibited broad spectrum antifungal activity. Because of its extraordinary potency, the triacid 1 and structurally related congeners such as 6,7dideoxysqualestatin H5 (DDSQ) $2^{7}$ represented exciting new therapeutic leads in the treatment of hypercholesterolemia and fungal infections. They possess a novel densely functionalised 2,8-dioxabicyclo[3.2.1]octane core and the development of a general synthetic route to this system represented a significant and worthwhile challenge to the synthetic chemist. ${ }^{8}$ 


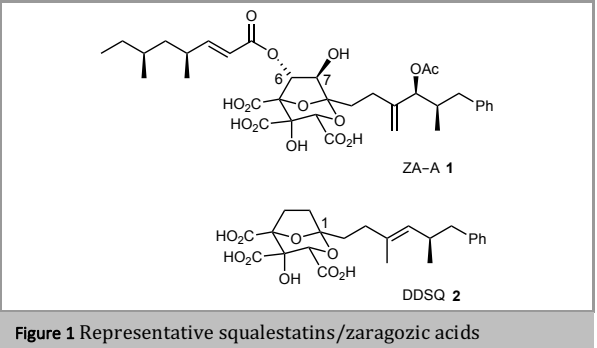

Analysis of the 2,8-dioxabicyclo[3.2.1] octane core 3 (Scheme 1) of the squalestatins as the acyclic keto-triol indicated that it might be obtained by rearrangement of a 6,8dioxabicyclo[3.2.1] octane 4. In turn, it was considered that the 6,8-dioxabicyclo[3.2.1]octane 4 could be prepared via carbonyl ylide 5 from the diazoketone diester 6 (PG = protecting group), potentially derived from natural $(R, R)$ tartaric acid, in a significant extension of Padwa's investigations into the generation and utility of carbonyl ylides.

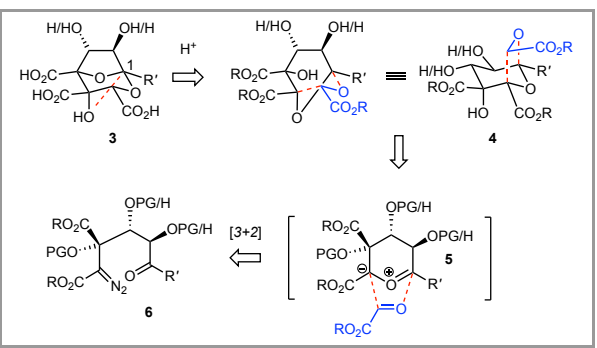

Scheme 1 Retrosynthetic analysis of the squalestatin core 3 (PG $=$ protecting group)

In the summer of 1993, with the support of a Nuffield Foundation undergraduate research bursary award, Vittorio Caprio (now at Manchester Metropolitan University) found that a glyoxylate can function as a dipolarophile with a carbonyl ylide and that it reacted with the desired regiochemistry, but undesired exo-/endo-stereochemistry. Nevertheless, this preliminary result assisted a research grant application to the UK Science and Engineering Research Council (SERC), which was assessed by an organic chemistry subcommittee who could recommend earmarked studentships to the chemistry committee (Figure 2). In the SERC's current successor, the EPSRC, long gone are the possibilities of obtaining earmarked studentships and the separate organic chemistry and chemistry committees.

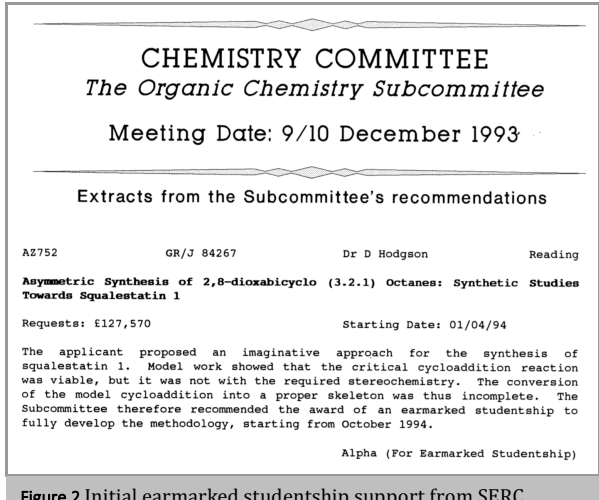

2 Racemic Model Studies to the Squalestatin/Zaragozic Acid Core

In the autumn of 1994, on the earmarked studentship, James Bailey commenced detailed investigations towards the synthesis of DDSQ 2 using carbonyl ylide cycloaddition and rearrangement chemistry as the key transformations to construct the 2,8-dioxabicyclo[3.2.1] octane skeleton. Initially, a racemic model study (the $\mathrm{C} 1$ alkyl side-chain $=\mathrm{Me}$ ) was investigated, starting with the known and readily prepared $\alpha$ diazoester 7 (Scheme 2). ${ }^{9}$ When $\alpha$-diazoester 7 reacted with freshly distilled methyl glyoxylate (9) in the presence of catalytic $\mathrm{Rh}_{2}(\mathrm{OAc})_{4}$, endo-cycloadduct $\mathbf{1 0}$ (with respect to the ylide-containing ring) was formed as a single regio- and stereoisomer (Scheme 2). The endo-orientation was attributed to the influence of a preferred secondary orbital interaction between the ester carbonyl of the methyl glyoxylate (in the $s$ trans conformation) and the ketone moiety of the ylide $\mathbf{8}$. Despite the incorrect stereochemistry, cycloadduct $\mathbf{1 0}$ was converted via lactone $\mathbf{1 1}$ to 6,8-dioxabicy clo[3.2.1]octane $\mathbf{1 2}$ to study the acid-catalysed rearrangement. At the time there were recent reports on the propensity of isomerisation of squalestatin-related 6,8- to 2,8-dioxabicyclo[3.2.1]octanes. Nicolaou and co-workers ${ }^{10}$ in their relay squalestatin synthesis observed that a more functionalised system favoured the desired 2,8-dioxygenated structure, while studies by Armstrong and Barsanti showed no preference at equilibrium between 2,8- and 6,8-isomers. ${ }^{11}$ With our system, rearrangement of alcohol 12 using cat. $\mathrm{HCl}$ (from $\mathrm{SOCl}_{2}$ in $\mathrm{MeOH})$ preferentially gave the desired 2,8dioxabicyclo[3.2.1] octane core $\mathbf{1 3}$ (12:13, 1:3), albeit still with the incorrect stereochemistry at $\mathrm{C} 4.9,12$ 


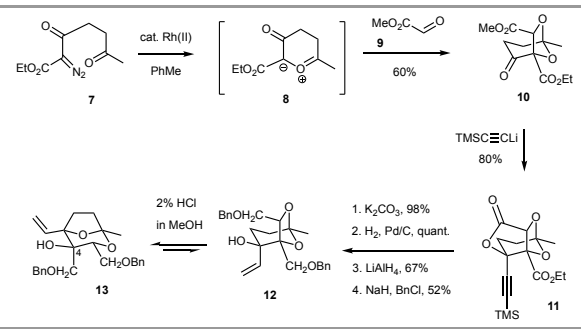

Scheme 2 Model study to the 2,8-dioxabicyclo[3.2.1]octane core 13

It was considered that the presence of the vicinal protected 6,7-diol functionality (as originally planned, $c f$ ylide $\mathbf{5}$, Scheme 1) might provide suitable steric congestion over the endo or back-side of the ylide ring, thus making the glyoxylate dipolarophile orient its ester group away from the ring to deliver the desired exo-cycloadduct. Dioxygenated diazo compounds 16 and 19 (Schemes 3 and 4) were prepared to examine the exo/endo and facial selectivity in the cycloaddition reaction. $\alpha$-Diazoester $\mathbf{1 6}$ was synthesised in three steps from the known tartrate-derived benzyl ether 14 (Scheme 3). Debenzylation of $\mathbf{1 4}$ followed by Swern oxidation gave an aldehyde which was directly homologated to $\beta$-ketoester $\mathbf{1 5}$ Diazotransfer using 4-nitrobenzenesulfonyl azide and $\mathrm{Et}_{3} \mathrm{~N}$ provided $\alpha$-diazoester 16 .

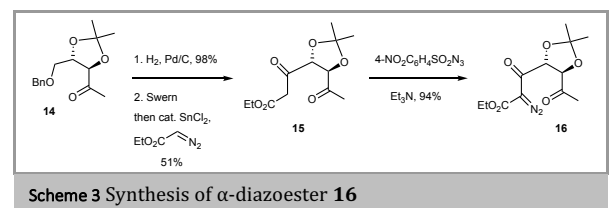

Bis-TBS ether 19 was accessed from known tartrate-derived lactone 17 in three steps (Scheme 4). Diol 17 was bis-silylated with TBSOTf, followed by addition of lithiated ethyl diazoacetate to give alcohol 18. Subsequent Dess-Martin oxidation gave bis-TBS ether 19.

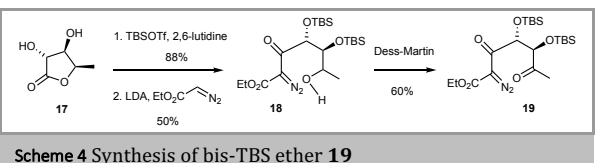

$\alpha$-Diazoesters 16 and 19 were found to be less reactive under the previously established cycloaddition conditions (Scheme 2 ), likely due to the steric congestion. After optimisation (higher concentration), cycloaddition of $\alpha$-diazoesters 16 and 19 with methyl glyoxylate gave single cycloadduct diastereomers (20 and 21, Scheme 5). Disappointingly, NMR studies indicated undesired stereochemistry in both cases. Cycloaddition using the more sterically demanding tert-butyl glyoxylate with $\alpha$-diazoester 19 also led to the same outcome (cycloadduct 22). The stereochemistry observed in the cycloadditions of $\alpha$-diazoesters 16 and 19 likely has its origins in that the lower face of the intermediate dipole is less hindered for the approach of the dipolarophile, whilst the glyoxylate ester still experiences secondary orbital overlap with the ylide ketone group.

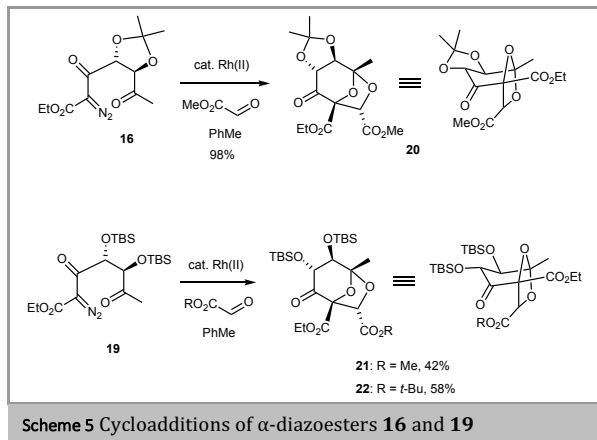

To control the endo:exo selectivity, a modified synthetic strategy needed to be pursued where the presumed secondary orbital overlap was eliminated with a bias to allow the formation of the exo-cycloadduct. During the above studies, Hashimoto and co-workers had reported that the configuration at $\mathrm{C} 4$ in more substituted diazotriester $\mathbf{2 3}$ was crucial to the success of related cycloadditions (Scheme 6).13 Cycloaddition of diazotriester 23 with $(E)$-hex-3-ene-2,5-dione occurred stereoselectively from the $\beta$-face of the ylide $\mathbf{2 4}$, thereby avoiding non-bonding interactions with the $\mathrm{C} 4$ pseudoaxial TMS ether, to generate 2,8-dioxabicyclo[3.2.1]octane $\mathbf{2 5}$ as a single diastereomer.

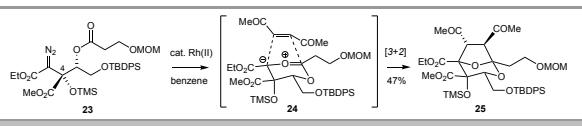

Scheme 6 Hashimoto and co-workers' cycloaddition approach to zaragozic acid $\mathrm{C}^{13}$

Encouraged by the above chemistry, it was hypothesised that modification of the $\beta$-keto group of the $\alpha$-diazoester 7 (Scheme 2 ) to more sterically demanding $\beta$-silyloxy functionality would remove the putative secondary orbital overlap effect and lead to the desired exo-cycloadduct. To examine facial and exo-endo selectivity issues, cycloaddition substrate keto diazodiester $\mathbf{3 0}$ was synthesised by Carol Villalonga-Barber in seven steps from $\gamma$-valerolactone 26 (Scheme 7). ${ }^{14,15}$ Thus, addition of $\alpha$-lithio methyl vinyl ether to lactone $\mathbf{2 6}$ gave, following secondary alcohol etherification using TESOTf, enone 27. Ozonolysis of enone $\mathbf{2 7}$ gave the $\alpha$-ketoester $\mathbf{2 8}$ which was treated with lithiated methyl diazoacetate to afford TBS ether 29 (1:1 mixture of diastereomers) after tertiary alcohol silylation. Selective TES ether desilylation and oxidation of the resulting secondary alcohol gave keto diazodiester $\mathbf{3 0}$. The lability of the secondary TES ether under mild conditions was crucial, as it, along with mild oxidation of the resulting intermediate secondary alcohol, allowed access to keto diazodiester $\mathbf{3 0}$ in 
which both the tertiary silyl ether and the diazo functionality were retained.

$$
\text { 26 }
$$

Scheme 7 Synthesis of a more sterically demanding $\beta$-silyloxy- $\alpha$ diazoester 30

Pleasingly, a significant result was obtained when keto diazodiester $\mathbf{3 0}$ reacted with methyl glyoxylate in the presence of cat. $\mathrm{Rh}_{2}(\mathrm{OAc})_{4}$, as it gave the required exo-cycloadduct $\mathbf{3 1}$ $(65 \%)$ as the major isomer along with others in a ratio of 12:1:1 (Scheme 8). Interestingly, decreasing the bulkiness of the $\beta$-siloxy functionality by using a TMS ether instead of a TBS ether led to a lower proportion of the exo-cycloadduct 31 (TMS instead of TBS) (8:1:1) in $63 \%$ yield. The cycloaddition preferentially occurs with glyoxylate approaching on the lesshindered face of the intermediate ylide (opposite to the silyloxy group) and exo to avoid steric interaction between the ester group of methyl glyoxylate and ester functionality at C5. After TBS-deprotection, acid-catalysed rearrangement with $2 \% \mathrm{HC}$ in $\mathrm{MeOH}$ (reflux, $15 \mathrm{~h}$ ) gave a mixture of the cycloadduct 32 with the desired rearranged core $\mathbf{3 3}$ and spirolactone $\mathbf{3 4}$ (32 33, 34, 69:21:10, respectively). After screening of a range of other acidic conditions $\left(2 \% \mathrm{HCl}\right.$ in $\mathrm{CHCl}_{3}$, $\mathrm{TfOH}$ in DMSO, CAS in $\mathrm{MeOH})$, rearrangement of cycloadduct 32 using Evans conditions (TFA $\left./ \mathrm{CH}_{2} \mathrm{Cl}_{2} / \mathrm{H}_{2} \mathrm{O}, 10: 20: 1\right)^{16}$ at $40{ }^{\circ} \mathrm{C}$ for $68 \mathrm{~h}$ gave the 2,8-dioxabicyclo[3.2.1]octane core $\mathbf{3 3}$ of the squalestatins/zaragozic acids at the correct tricarboxylate oxidation level in $54 \%$ yield ( $83 \%$ based on recovered 32 ) That acid-catalysed equilibrium had been reached was established by subjecting $\mathbf{3 3}$ to same acidic conditions, which returned the same 66:34 ratio of 33:32, respectively (Scheme 8).

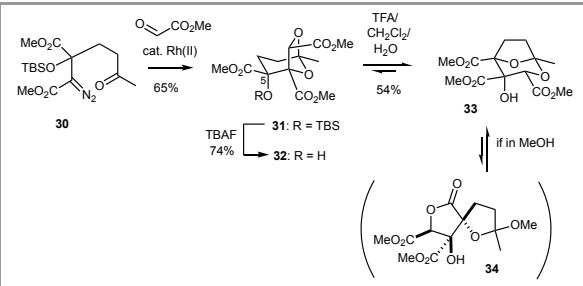

Scheme 8 Successful cycloaddition and rearrangement to squalestatin core 33

\section{Asymmetric Model Studies to a Keto $\alpha$-Diazoester} 3.1 Dialkyl Squarate Desymmetrisation

Having developed a racemic strategy to the core of the squalestatins/zaragozic acids (Scheme 8), the next step was to control the absolute stereochemistry of $\alpha$-diazoester $\mathbf{3 0}$. Initially, Herman Sintim (currently at Purdue University) envisaged that dialkyl squarates could be elaborated into the desired ketodiester motif via monoaddition of an organolithium to a dialkyl squarate (Scheme 9), followed by an ozonolytic cleavage of the squarate double bond, eventually carrying out the organolithium addition in an asymmetric manner.

$$
\text { 等 }
$$

Scheme 9 Retrosynthetic analysis of $\mathbf{3 0}$ based on a squarate approach

Regioselectivity in the addition of alkyllithiums to squarates is generally the desired 1,2-pathway. ${ }^{17}$ To examine if we could access the requisite $\varepsilon$-keto- $\alpha$-diazoester motif from dialkyl squarates, a TES-substituted butyl side-chain $\mathbf{3 7}$ was introduced onto the squarate 36a to obtain the 1,2-addition product 35 (Scheme 10). ${ }^{18}$ After silylation and ozonolysis of silyl ether 38, the resulting sensitive $\alpha$-ketosuccinate 39 was best taken directly to hydrazone $\mathbf{4 0}$. Et $t_{3} \mathrm{~N}$ was used to carry out the Bamford-Stevens-type sulfinate elimination to give the corresponding $\alpha$-diazoester $\mathbf{4 1}$ (39\% over 3 steps). A small amount of the diazodiketoester $\mathbf{2 9}$ still retaining the TES group as also isolated (8\%). Both diazoesters (41 and 29) could be converted to the desired $\varepsilon$-keto- $\alpha$-diazoester $\mathbf{3 0}$ (Scheme 7).

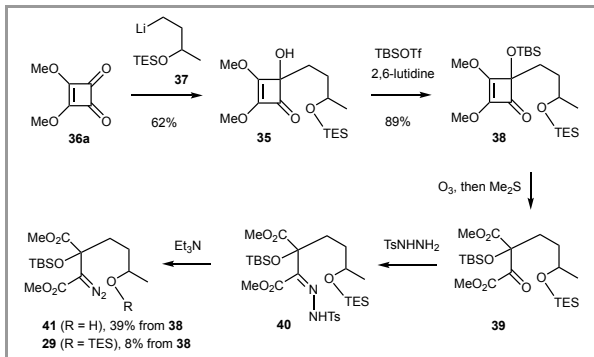

Scheme 10 Synthesis of diazoesters $\mathbf{4 1}$ and $\mathbf{2 9}$ from squarate 36 .

Having established that dimethyl squarate $\mathbf{3 6 a}$ could be transformed into $\alpha$-diazoester $\mathbf{3 0}$, we considered squarate addition by an organolithium in the presence of a chiral ligand $\left(L^{*}\right)$ as a potential asymmetric variation towards these systems. The addition of butyllithium to di-tert-butyl squarate 36b (Scheme 11) was studied in the presence of representative chiral ligands. 18 of the ligands screened, bisoxazoline L1 displayed the highest (although still modest) enantioselectivity (er 63.5:36.5), however in low conversion (25\% yield). Also, 
the latter result was observed with 3 equiv of $\mathbf{L 1}$ relative to BuLi; equimolar quantities gave a lower er (55:45).

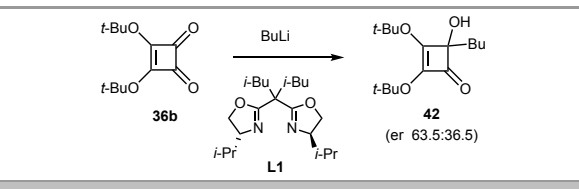

Scheme 11 Asymmetric addition of alkyllithium to squarate $\mathbf{3 6 b}$

Given the low asymmetric induction observed using an organolithium with various chiral ligands, we also considered the use of organozincs. Reaction between di-tert-butyl squarate 36b and $\mathrm{Et}_{2} \mathrm{Zn}$ ( 3 equiv) in the presence of $\mathrm{Ti}(i-\mathrm{PrO})_{4}(1.7$ equiv) and ligands $\mathbf{L} 2$ or $\mathbf{L} 3(20 \mathrm{~mol} \%)$ in toluene at $60^{\circ} \mathrm{C}$ gave the best conversion to the desired 1,2-mono-addition product ethylated squarate $43(\sim 60 \%$, Scheme 12$)$, with ers of 65.5:34:5 and 59:41, respectively. Variation of the reaction conditions with camphorsulfonamide $\mathbf{L 3}$ at $60{ }^{\circ} \mathrm{C}$ and higher ( $60 \mathrm{~mol} \%$ ) or lower ( $5 \mathrm{~mol} \%$ ) chiral catalyst loadings gave ers for 43 of 67.5:32.5 and 59:41. It was notable that the reaction of $\mathbf{L 3}$ at $60^{\circ} \mathrm{C}$ for $20 \mathrm{~h}$ was shown to be scale dependent: at 0.2 mmol scale, ethylated squarate $\mathbf{4 3}$ was isolated in only $5 \%$ yield (er 65.5:34.5), whereas at $3 \mathrm{mmol}$ scale a $51 \%$ yield of 43 (er 58:42) was obtained. Instability of the ethylated squarate 43 on silica likely contributed to the variation in isolated yields.

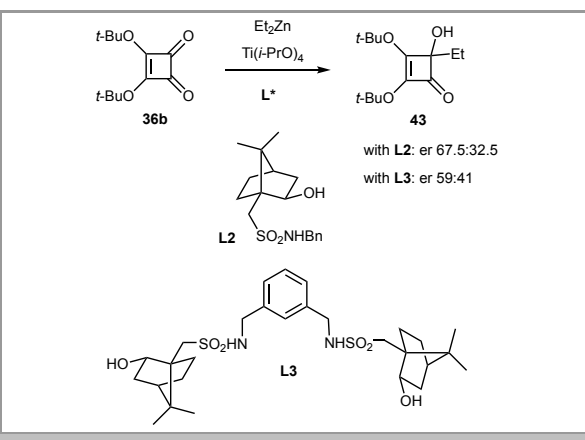

Scheme 12 Asymmetric addition of dialkylzinc to squarate $\mathbf{3 6 b}$

As the above route from squarates showed only modes asymmetric induction, an alternative asymmetric approach was investigated to the desired $\varepsilon$-keto- $\alpha$-diazoesters.

\subsection{Tartrate Alkylation}

In 1981, Seebach and Naef reported that the lithium enolate of $(R, R)$-tartrate acetonide $(\mathbf{4 4} \rightarrow \mathbf{4 5})$ could be trapped in a stereoselective manner with reactive alkyl halides, such as allylic halides and benzylic halides (but not with n-alkyl halides), to give the major alkylated diastereomer 46 ( $\sim 80: 20$ dr, Scheme 13). ${ }^{19,20}$

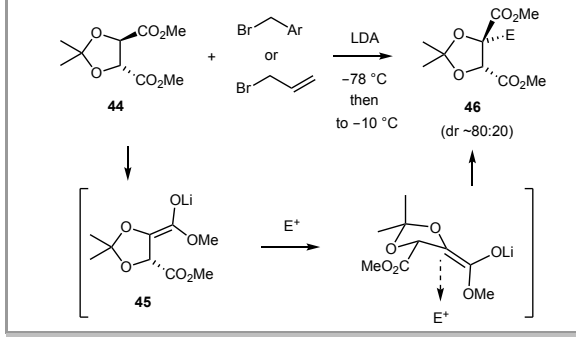

Scheme 13 Contrasteric alkylation developed by Seebach and coworkers ${ }^{19,20}$

An alternative and asymmetric route to $\varepsilon$-keto $\alpha$-diazoester 30 was designed involving Seebach's chemistry (Scheme 14). If an alkylated tartrate $\mathbf{4 6}$ could be accessed from a silyloxysubstituted alkyl iodide and subsequently oxidised through a second enolate to lactol $\mathbf{4 7}$, then this would give $\alpha$-ketoester 48 after acetonide removal. This approach was considered more feasible than acetonide deprotection of alkylated tartrate 46 (related systems requiring prolonged heating with acid) followed by selective alcohol oxidation. $\alpha$-Ketoester $\mathbf{4 8}$ should in principle be a progenitor to the desired $\varepsilon$-keto $\alpha$-diazoester 30 ( $c f$ Schemes 7 and 10$)$

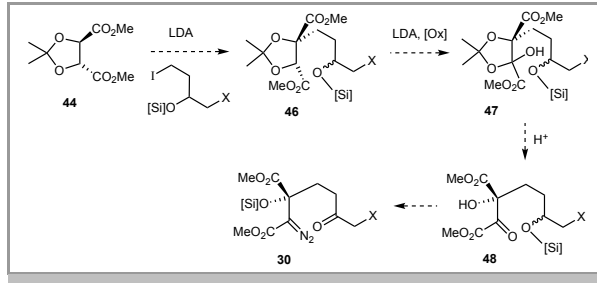

Scheme 14 Tartrate alkylation strategy to $\varepsilon$-keto- $\alpha$-diazoester 30

Although Seebach had originally reported that the alkylation of the lithium enolate of tartrate acetonide $\mathbf{4 4}$ was only feasible with reactive halides, we were pleased to find after reaction adjustment (prolonged reaction time at $-78{ }^{\circ} \mathrm{C}$ before quenching at the same temperature) that $(R, R)$-tartrate and a 3-silyloxy-1-iodobutane did generate alkylated tartrate $\mathbf{4 6}$ and the alkylation occurred exclusively cis to the unenolised ester group (Scheme 15).21 Access to hydroxy diazoester $\mathbf{5 0}$ was achieved by oxidation of the lithium enolate of the alkylated tartrate 46 using freshly prepared $\mathrm{MoOPh}, 22$ followed by acidcatalysed elimination of acetone from the resulting hydroxy acetonide. The acidic conditions $(1 \%$ aq $\mathrm{HCl})$ removed both the acetonide and TES groups in hydroxy acetonide $\mathbf{4 7}$. Subsequent silylation using TESOTf gave the bis TES ketone $\mathbf{4 9}$, which was converted to diazo alcohol $\mathbf{5 0}$ (17\% from 47). The efficiency of the sequence from hydroxy acetonide $\mathbf{4 7}$ to diazo alcohol $\mathbf{5 0}$ could be improved (to $37 \%$ ) using $\mathrm{ZnCl}_{2}$ for the initial deprotection and TESCl in the silylation; the latter minimises formation of the undesired silylated six-membered lactol form of $\mathbf{4 9}$. 


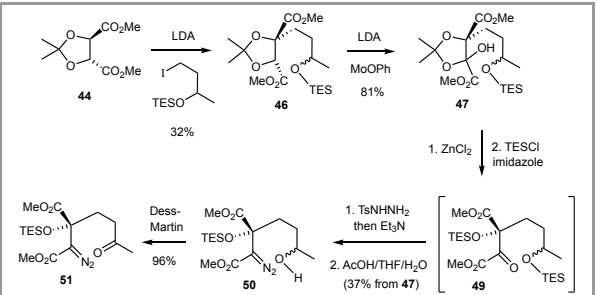

Scheme 15 Tartrate approach towards enantioenriched $\alpha$ diazoester $\mathbf{5 1}$

\subsubsection{Further Studies on Seebach's Alkylation Chemistry}

Alkylation of dimethyl tartrate acetonide $\mathbf{4 4}$ with other primary 'non-activated' alkyl iodides was also achieved at -78 ${ }^{\circ} \mathrm{C}$ (with work-up at the same temperature) in acceptable yields; small quantities of trans-dialkylated products $\mathbf{5 2}$ were also isolated (Scheme 16).21

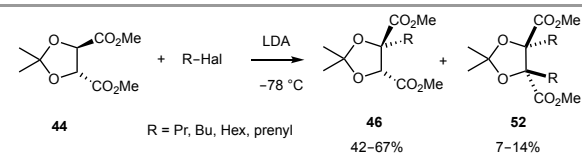

\section{Scheme 16 Tartrate alkylation with $n$-alkyl halides}

Studies were carried out with the aim of rationalising the reaction pathway leading to trans-dialkylated by-product $\mathbf{5 2}$ during the alkylation process, and whether the dialkylated byproduct was racemic or obtained in high enantioenrichment. Chiral HPLC studies showed that the observed transdipropylated material 52 (52a: $\mathrm{R}=\mathrm{Pr}$ ) was racemic (52:48 er), likely forming via dienolate $\mathbf{5 4}$ (Scheme 17). Further investigation showed that when monopropylated tartrate 46 (46a: $\mathrm{R}=\mathrm{Pr}$ ) was subjected to propylation under same monoalkylation conditions $\left(-78{ }^{\circ} \mathrm{C}\right)$ this mainly returned starting 46a (68\%). However, propylation of the monopropylated tartrate 46a was achieved in 98:2 er (34\% yield) when the reaction mixture was warmed to $-50{ }^{\circ} \mathrm{C}$. Thus, the ability to form the dienolate $\mathbf{5 4}$ to some extent at $-78{ }^{\circ} \mathrm{C}$ (Scheme 17) led to racemic dialkylated product; and also, once monoalkylation has occurred from the mono-enolate tartrate 45, then 46a is not readily deprotonated unless warmed to -50 ${ }^{\circ} \mathrm{C}$. These observations imply that generation of $(R, R)$ - ( or $(S, S)$ ) $C 2$-symmetric dialkylated tartrates is best carried out through two separate reactions.

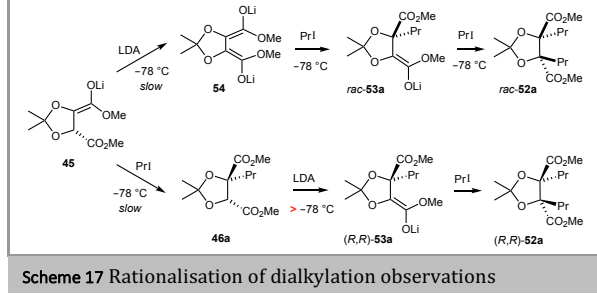

To extend the tartrate alkylation scope further, we examined the feasibility of preparing the epimers $(R, S)$ of mono-alkylated tartrate products by epimerisation at the $C 3$ position. The $2 R, 3 S$ stereochemistry of the monoalkylated tartaric acid motif is also directly present in several other natural products. ${ }^{23}$ Alkylated tartrate $46(\mathrm{R}=$ prenyl) was exposed to $\mathrm{NaOMe}$ in $\mathrm{MeOH}(0.5 \mathrm{M})$ at room temperature which gave only partial epimerisation (46:epi-46 75:25). However, the equilibrium shifted to a 25:75 ratio in favour of epi-46 in $\mathrm{MeOH}(0.06 \mathrm{M})$ at reflux for $30 \mathrm{~h}$ (Scheme 18). That true equilibrium had been reached was established by treating epi-46 to these latter reaction conditions, which returned the same 25:75 ratio of 46:epi-46. Epimerisation of other monoalkylated tartrates 46 $(\mathrm{R}=\mathrm{Pr}, \mathrm{Bn}$, butenyl) gave similar equilibrium ratios, providing chromatographically separable epi-46 in 54-67\% yield.

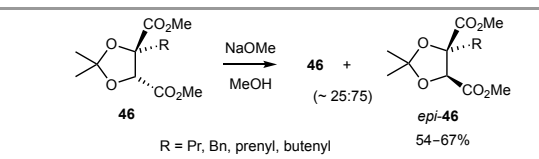

Scheme 18 Epimerisation of monoalkylated tartrates

Base-induced epimerisation of the monoalkylated tartrates favours cis-disposition of the ester groups on the fivemembered ring, thereby accessing the predominant stereochemistry found in several substituted tartaric acidcontaining natural products. These findings on origins of the dialkylated by-products, and on epimerisation conditions of the monoalkylated tartrates, broaden the scope and understanding of Seebach's alkylation chemistry.

\section{Failure at the Penultimate Step to DDSQ}

With encouragement from the above model studies (Schemes 8 and 15), Herman Sintim proceeded to address the total synthesis of DDSQ (2) by alkylative introduction of the full C1 side-chain $\mathbf{5 8}$ to tartrate acetonide $\mathbf{4 4}$, as outlined in Scheme 19. 


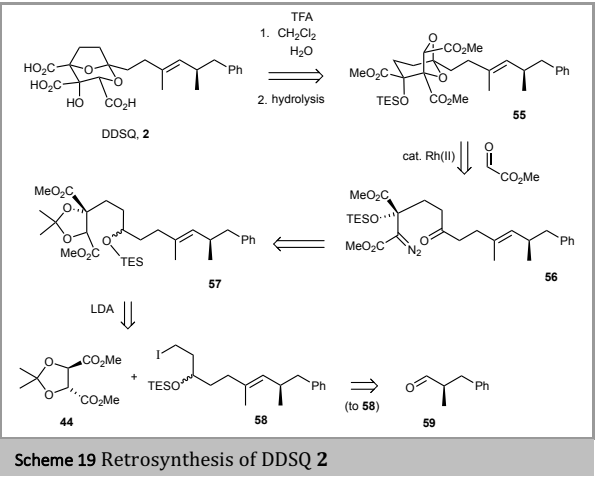

The $\mathrm{C} 1$ side-chain iodide $\mathbf{5 8}$ was prepared in 7 steps from $(R)$ aldehyde 59 (Scheme 20). ${ }^{24}$ Wittig olefination of aldehyde $\mathbf{5 9}$ with ylide $\mathbf{6 0}$, then 1,2-reduction with DIBAL-H of the resulting unsaturated ester then $\mathrm{OH} \rightarrow \mathrm{Br}$ conversion gave allylic bromide 62. Bromide 62 was then coupled with the dianion of ethyl acetoacetate $\mathbf{6 3}$, to produce $\beta$-ketoester $\mathbf{6 4}$ in $79 \%$ yield. Following Soai and Oyamada's procedure, ${ }^{25} \beta$-ketoester 64 was reduced to 1,3-diol $\mathbf{6 5}$ and iodination of the latter gave mono iodide 66 , along with some diiodide $67(\sim 23 \%)$. Finally, TES protection of mono iodide $\mathbf{6 6}$ gave the desired side-chain iodide $\mathbf{5 8}$ (Scheme 20).

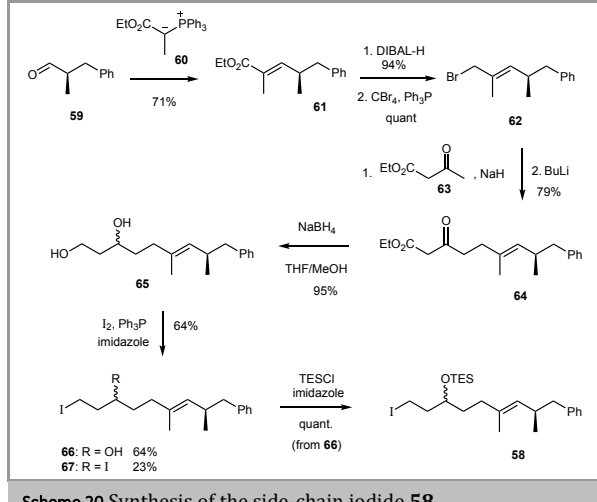

Scheme 20 Synthesis of the side-chain iodide $\mathbf{5 8}$

Elaboration of side-chain iodide $\mathbf{5 8}$ to the cycloadduct $\mathbf{5 5}$ mostly followed the chemistry developed in the earlier model studies (Scheme 15). Alkylation of lithiated dimethyl L-tartrate acetonide $\mathbf{4 4}$ with iodide $\mathbf{5 8}$ gave the alkylated tartrate $\mathbf{5 7}$ in $40-70 \%$ yield (Scheme 21). Then, the enolate of alkylated tartrate 57 was treated with $\mathrm{MoOPH}$, thereby accessing hydroxylated acetonide 68 . In the model study, $\mathrm{ZnCl}_{2}\left(\right.$ or $\left.\mathrm{AlCl}_{3}\right)$ were successfully used to hydrolyse hydroxylated acetonide to keto-ester, followed by TES-silylation $(\mathbf{4 7 \rightarrow 4 9}$, Scheme 15$)$. Unfortunately, these Lewis acids were unsuitable for the hydrolysis of the more elaborate hydroxylated acetonide $\mathbf{6 8}$, leading to a $\sim 70: 30$ mixture of 69 and 70 respectively. However, cleavage of the isopropylidene moiety could be achieved under acidic conditions $\left(0.1 \mathrm{M} \mathrm{H}_{2} \mathrm{SO}_{4}\right.$ in $\left.\mathrm{MeOH}\right)$ to give lactol 71. Treatment of lactol $\mathbf{7 1}$ with TESCl in the presence of imidazole gave ketone 72. Hydrazone condensation of ketone $\mathbf{7 2}$ with tosylhydrazide gave a hydrazone which on exposure to $\mathrm{Et}_{3} \mathrm{~N}$ gave a diazodiester $\mathbf{7 3}$ with small amount of $\mathrm{C} 6$ desilylated material. The diazodiester 73 was completely desilylated at the secondary ether with a 1:2:1 mixture of AcOH:THF: $\mathrm{H}_{2} \mathrm{O}$, and then Dess-Martin oxidation led to the required cycloaddition precursor, diazoketone 56. Pleasingly, and following earlier conditions (Scheme 8), 1,3-dipolar cycloaddition of diazoketone $\mathbf{5 6}$ using cat. $\mathrm{Rh}_{2}(\mathrm{OAc})_{4}$ in the presence of methyl glyoxylate gave the desired exo-cycloadduct $\mathbf{5 5}$. 


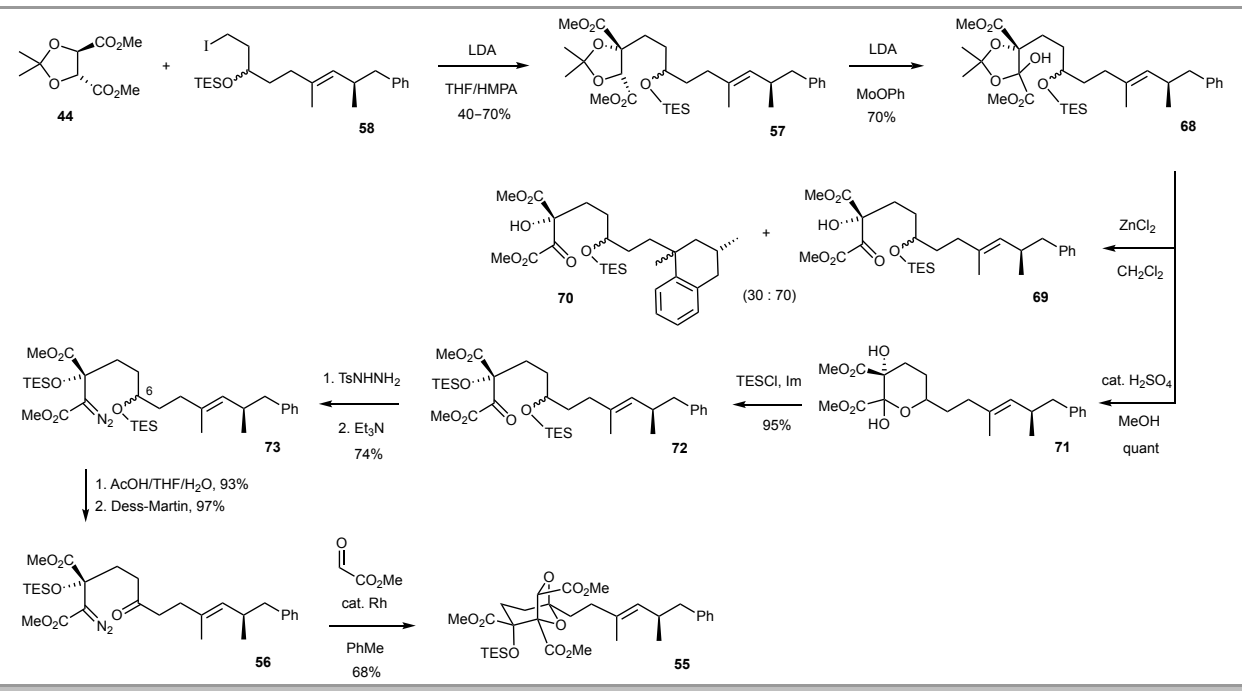

Scheme 21 The first approach towards DDSQ (2)

Following the model study (Scheme 8), deprotection of TES ether 55, and then acid-catalysed rearrangement was anticipated to give the desired DDSQ triester $\mathbf{7 4}$ (Scheme 22). However, when cycloadduct $\mathbf{5 5}$ was subjected to the rearrangement conditions (TFA $/ \mathrm{CH}_{2} \mathrm{Cl}_{2} / \mathrm{H}_{2} \mathrm{O}$ ) following TBAFinduced desilylation, a mixture of two compounds with loss of the unsaturation in the side-chain was obtained. Very disappointingly, variation in the reaction conditions (temperature, time, acid and ratio of TFA with $\mathrm{CH}_{2} \mathrm{Cl}_{2} / \mathrm{H}_{2} \mathrm{O}$ ) all failed to give the desired rearranged material.

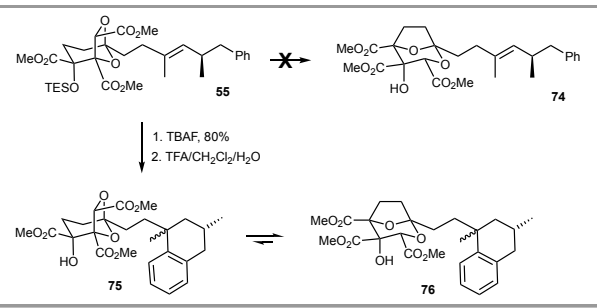

Scheme 22 Undesired loss of the alkene moiety

The undesired compound mixture generated under the rearrangement conditions was considered to be tetralins $\mathbf{7 5}$ and

76, arising from TFA-induced generation of a tertiary carbocation at the acid-labile trisubstituted alkene which was subsequently trapped by the aromatic ring. In support of the above analysis, exposing a simpler model system, 2,4-dimethyl5-phenyl-2-pentene (77), to the rearrangement conditions [TFA: $\mathrm{CH}_{2} \mathrm{Cl}_{2}: \mathrm{H}_{2} \mathrm{O}(10: 20: 1), 40{ }^{\circ} \mathrm{C}, 68 \mathrm{~h}$ ] gave the tetralin 78 in $95 \%$ yield (Scheme 23 ). ${ }^{26}$

Template for SYNTHESIS @ Thieme Stuttgart $\cdot$ New York 2020-11-05

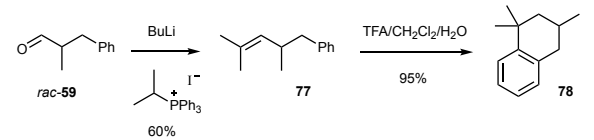

Scheme 23 Preparation and acid-catalysed cyclisation of alkene

From the above studies, the alkene moiety is highly reactive to Friedel-Crafts cyclisation: this occurred within $5 \mathrm{~min}$, whereas the desired rearrangement requires 48-62 h. Failure was particularly painful at the penultimate hurdle. At this point in time alternative strategies were considered to overcome the issue: either the use of an alkene protecting-group approach (Scheme 24, PG = 'protecting-group'), or introduction of the alkene bearing side-chain after the acidic rearrangement step (Scheme 24, X = halide). However, 15 years would elapse before Herman Sintim saw elements of the strategy he developed being applied in a successful total synthesis. 


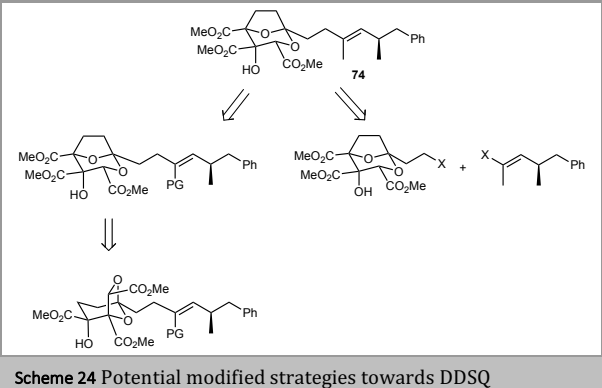

5 Second-Generation Approach to DDSQ: a Bromide Substituent Strategy

We first focused on the issue of how to directly protect an electron-rich $\mathrm{C}=\mathrm{C}$ under the acid-catalysed rearrangement conditions. It was considered that a temporary halide substituent on the alkene (Scheme 25) could reduce its propensity to protonation. In this strategy, post-rearrangement methylation cross-coupling/esters hydrolysis would allow access the natural product from bromide $\mathbf{7 9}$. Cycloadduct $\mathbf{8 0}$ was considered as being accessible through tartrate alkylation with $Z$-alkenyl bromide-bearing side-chain 81, in a similar manner to the route developed by Sintim (Scheme 21).

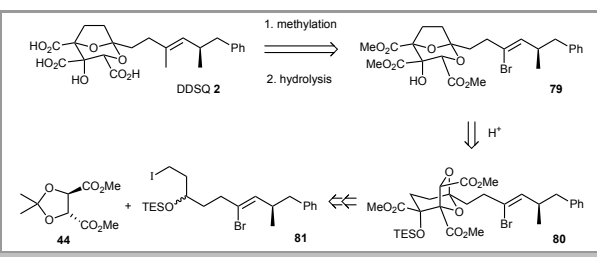

Scheme 25 Alkene protection strategy to DDSQ

$Z$ - $\alpha$-Bromo- $\alpha, \beta$-unsaturated esters are typically prepared directly from aldehydes by Wittig olefination. ${ }^{27,28}$ With aldehydes and brominated ylide $\mathbf{8 2}$ (Scheme 26), the reaction normally produces predominantly, but not exclusively, the $Z$ isomer. Preliminary studies by Hamad Al-Mamari to generate $Z$ bromoalkene $\mathrm{rac}-\mathbf{8 3}$ from aldehyde $\mathrm{rac}-\mathbf{5 9}$ led to the use of 2.5 equiv of ylide 82: in benzene or $\mathrm{MeCN}$ at reflux for $48 \mathrm{~h}$, ester rac-83 was formed in $30 \%$ and $88 \%$ yields, respectively ( $Z: E$, $8: 1$ and $6: 1$, respectively), with the geometric isomers being separable by chromatography ( $75 \%$ yield of $Z-83$ isolated from the reaction in $\mathrm{MeCN}$ ). ${ }^{29}$

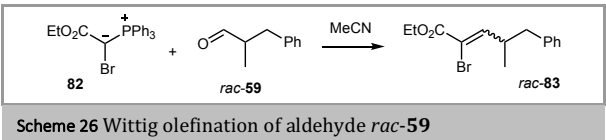

Alkenyl bromides 84 and $\mathbf{8 5}$ (prepared from rac-83) were used in a model study to examine the viability of alkene protection from an acid (TFA) by the presence of a bromide substituent, and then whether the required methyl group could be installed in a stereoretentive manner (Scheme 27). Pleasingly, reaction of 1,3-diol 84 under the required acidic rearrangement conditions gave the bistrifluoroacetate 86 (quant.), in which the alkenyl bromide was unaffected. Moreover, stereoretentive Suzuki reactions between the 1,3-diol 84 or bis-TBS ethers 85 and the borinate ester $\mathbf{8 7}$ gave $E$-alkenes $\mathbf{8 8}$ and $\mathbf{8 9}$ in $\mathbf{8 1 \%}$ and quantitative yields, respectively.

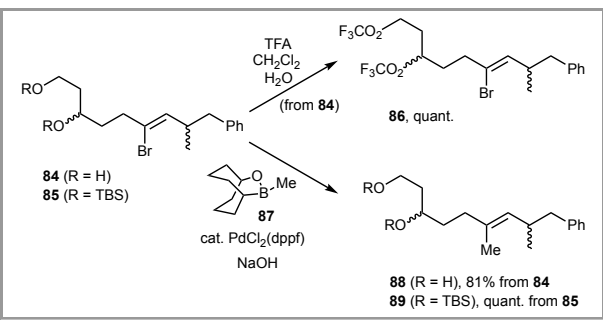

Scheme 27 Stability of alkenyl bromide functionality under the acidic rearrangement conditions and lability to stereoretentive methylation

With preservation of alkenyl bromide functionality under the rearrangement reaction conditions demonstrated (Scheme 27), olefination of the $R$-aldehyde $\mathbf{5 9}$ was examined. Wittig homologation with ylide $\mathbf{8 2}$ and aldehyde $R-\mathbf{5 9}(95 \%$ ee) led to erosion of enantiointegrity in the resulting bromo ester $R-\mathbf{8 3}$ ( $86 \%$ ee). The combination of modest $E / \mathrm{Z}$-stereocontrol and reduction in enantiopurity during formation of bromo ester $\mathbf{8 3}$ through Wittig chemistry, led us to consider alternative ways of achieving the same transformation that might avoid these issues. Chromium(II)-mediated or -catalysed olefination using trihaloacetates (mainly trichloroacetates, and on $1 \mathrm{mmol}$ scale) has been reported by Falck, Mioskowski and co-workers to produce exclusively $Z$ - $\alpha$-haloacrylates. ${ }^{30}$ When ethyl tribromoacetate reacted with aldehyde $\mathbf{5 9}(0.8 \mathrm{mmol}$ scale), the desired $Z$-bromo ester $\mathbf{8 3}$ was exclusively formed in $65 \%$ yield (Scheme 28), and with no loss of enantiointegrity. However, scale-up of the catalysed reaction $(0.2$ mole of aldehyde 59) gave ester $\mathbf{8 3}$ in a reduced $40 \%$ yield.

$$
\overbrace{R-59}^{\mathrm{Ph}} \underset{\substack{\mathrm{Mn}, \mathrm{Me}_{3} \mathrm{SiCl} \\ 40 \%(0.2 \mathrm{mmol})}}{\stackrel{\mathrm{EtO}_{2} \mathrm{CCBr}_{3}, \mathrm{CrCl}_{2}}{\longrightarrow}} \mathrm{EtO}_{\mathrm{Br}} \overbrace{R-83}^{\mathrm{Ph}}
$$

Scheme 28 Chromium(II)-catalysed olefination of aldehyde $R-59$

Encouraged by the model studies (Scheme 27), bromo ester $R$ $\mathbf{8 3}$ was converted to cycloadduct $\mathbf{8 0}$ (Scheme 29) in a manner similar to Sintim's work (Schemes 20 and 21). After desilylation, the key rearrangement of the resulting cycloadduct $\mathbf{9 0}$ gave a mixture of the desired 2,8-dioxabicyclo[3.2.1]octane 79 and recovered 90 (in 60:40 ratio, respectively), importantly with preservation of the alkenyl bromide. The final steps of the total synthesis were planned to be a one-pot tandem Suzuki-Miyaura methylation and ester hydrolyses. Unfortunately, no evidence of DDSQ (2) was observed when the resulting rearrangement 
reaction mixture $(\mathbf{7 9}+\mathbf{9 0})$ was submitted to Suzuki-Miyaura conditions. Lack of material as well as time constraints did not allow additional investigation of this reaction by Al-Mamari, giving another painful end to the synthesis campaign, now falling at the final hurdle.

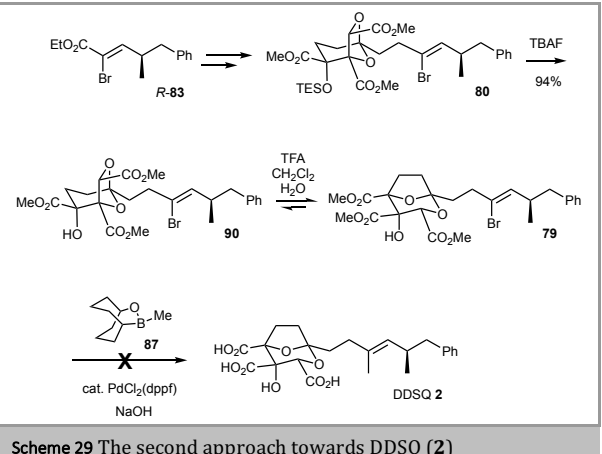

5.1 Stereoselective Routes to $\boldsymbol{E}$-Alkenyl Halides via $\boldsymbol{\beta}$-0xido Phosphonium Ylides

Tanzeel Arif continued the project, with the initial aim to improve the synthesis of the $Z$-alkenyl bromide side-chain by avoiding the bottle-neck chromium(II)-catalysed olefination (Scheme 28). If successful, it was expected that this should lead to enough material to investigate the problematic crosscoupling methylation step and complete the DDSQ synthesis. An $\alpha$-substitution plus carbonyl olefination via $\beta$-oxido phosphonium ylide (SCOOPY) reaction ${ }^{31}$ was investigated as a convergent and stereoselective route to trisubstituted $Z$ bromoalkenes. However, in a model study, reaction of 1,2 dibromotetrafluoroethane (93) with $\beta$-lithiooxyphosphonium ylide 92 gave $E$-bromoalkene 94 (96:4) (Scheme 30),32 instead of the $Z$-isomer (alkyl groups mutually trans) as anticipated for a Wittig-Schlosser-type reaction.

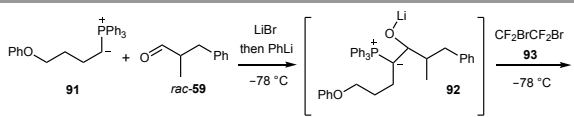

$$
\begin{aligned}
& \overbrace{65 \%, E: Z 96: 4}^{\mathrm{Ph}}
\end{aligned}
$$

Scheme 30 Model Wittig-Schlosser-type (SCOOPY) reaction with unexpected stereochemical outcome

This surprising result diverted our attention towards investigating the reaction of $\beta$-lithiooxyphosphonium ylides with a variety of electrophiles. Due to the importance of stereodefined alkenyl bromides and iodides as precursors to a host of organometallic intermediates, we first sought to investigate further the scope of this process towards these alkenes. A variety of alkylidene(triphenyl)phosphoranes were examined (Table 1) with aromatic (entries 1-3), heteroaromatic (entries 4-6) and aliphatic aldehydes (entries 7-9). ${ }^{33}$ The stereochemical outcome of subsequent bromination or iodination (using $\mathrm{I}_{2}$ ) of the intermediate $\beta$-oxido ylides was acutely sensitive to the size of the alkylidene: increasing the latter beyond ethylidene led predominantly to $E$-alkenyl bromides and iodides (entry 1, compared to entries 2-9).

Table 1 Alkenyl halides from aldehydes

Inspired by the above observations and with consideration of the possible origins of stereoselectivity on trapping $\beta$-lithiooxy phosphonium ylides with electrophiles 33 led Arif to spend the majority of his remaining doctoral studies developing procedures for and applications of stereoselective syntheses of disubstituted $Z$-allylic esters ${ }^{34}$ and trisubstituted $Z$-allylic esters (Scheme 31). ${ }^{35}$

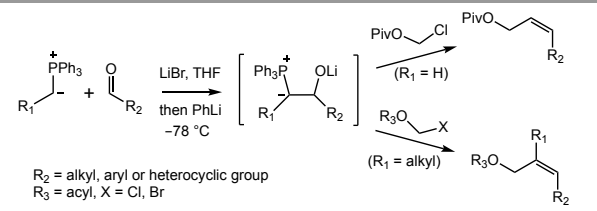

Scheme 31 Stereoselective synthesis of di- and trisubstituted Zallylic esters 


\subsection{Back to DDSQ synthesis}

As a main part of his doctoral studies, Hasanain Almohseni began reinvestigating in 2016 the bromination strategy to hopefully reach the natural product target (DDSQ). The bromoalkene route described earlier (Section 5) suffered from a low yield of the $Z$-alkenyl bromide-bearing side-chain $\mathbf{8 1}$ and the final problematic methylation/hydrolysis step $(\mathbf{7 9 \rightarrow 2}$, Scheme 29). To allow greater throughput of the aldehyde $\mathbf{5 9}$ to $Z$-bromo ester 83 on scale, and under experimentally more straightforward conditions, a two-step procedure (Scheme 32) involving olefination with the more reactive unbrominated ylide $\mathbf{9 5}$, to give the E-enoate 96 followed by brominationdehydrobromination was developed. This strategy has previously been shown to proceed without erosion of enantiointegrity with such an ester-stabilised ylide on a related $\alpha$-methyl aldehyde, ${ }^{36,37}$ and was a practical solution to efficiently generating Z-bromo ester $\mathbf{8 3}$ (94\% yield) from aldehyde $\mathbf{5 9}$.

$$
\text { (S) }
$$

Scheme 32 Olefination and bromination/dehydrobromination of aldehyde 59, leading to methylation substrate $\mathbf{7 9}$

Bromo ester $\mathbf{8 3}$ was then advanced to the methylation substrate 79 in a similar manner to Sintim's (Scheme 21) and Al-Mamari's studies (Scheme 29). Unfortunately, again there was no evidence of DDSQ (2) with pure $\mathbf{7 9}$ under the original one-pot tandem Suzuki-Miyaura methylation and esters hydrolysis conditions of Scheme 29. It was considered that the presence of aq. $\mathrm{NaOH}(3 \mathrm{M}$ ) complicated the reaction by hydrolysis of some of the ester groups, especially the least hindered ester at $\mathrm{C} 3$. Softer/weaker bases such as powdered $\mathrm{K}_{2} \mathrm{CO}_{3}$ or $\mathrm{K}_{3} \mathrm{PO}_{4}$ were examined (on bromoalkene 97, as a model); however, methylation did not proceed to completion. Fürstner and Seidel had extended the scope of the Suzuki reaction by using $B-\mathrm{MeO}-$ $9 \mathrm{BBN}$ as a vehicle to transfer an alkyl group through formation of a borinate complex (eg 98, Scheme 33) with the corresponding organometallic reagent, which then underwent transmetallation with an organopalladium complex in the absence of base. ${ }^{38}$ When freshly prepared borinate complex 98 (from $B$-Me0-9BBN and $\mathrm{MeLi}$ ) was refluxed with bromoalkene $85 \mathrm{in} \mathrm{THF}$ in the presence of $10 \% \mathrm{PdCl}_{2}$ (dppf), only a moderate amount of $E$-alkene 89 was detected (37\%). However, when anhydrous NaOMe (1.5 equiv) was added to accelerate the reaction, the coupling proceeded smoothly, to give alkene $\mathbf{8 9}$ in good yield (75\%, Scheme 33 (A)); similarly, alcohol 97 (as a free alcohol is present in the target substrate 79) gave alcohol 99 (76\%). Disappointingly, using this modified methylation crosscoupling on the real system $\mathbf{7 9}$, resulted in only decomposition of the starting material. A new model substrate $\mathbf{1 0 0}$ (Scheme 33 (B)), which shared more functional groups present in the precious real substrate $\mathbf{7 9}$, was then studied. Changing the base from $\mathrm{NaOMe}$ to aq. $\mathrm{Cs}_{2} \mathrm{CO}_{3}(3 \mathrm{M}$ ) in THF/DMF led to complete conversion to the desired product $\mathbf{5 7}$, but only in $45 \%$ yield. However, the yield was improved to $75 \%$ by adding 0.3 equiv of co-ligand $\mathrm{Ph}_{3}$ As.

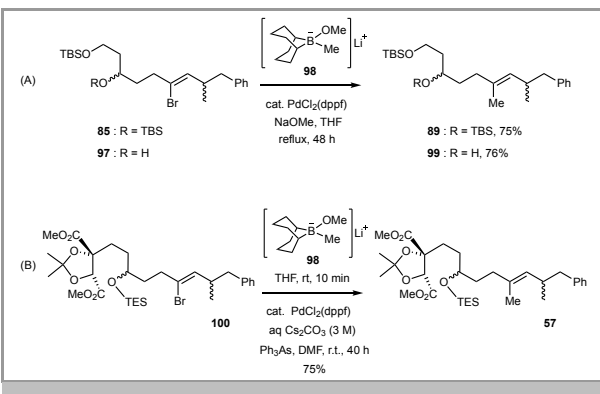

Scheme 33 Further methylation model studies

Unfortunately, application of the methylation cross-coupling conditions used with substrate 100 (Scheme 33 (B)), to 2,8dioxabicyclic core $\mathbf{7 9}$ was not successful. ${ }^{1} \mathrm{H}$ NMR analysis of the obtained mixture indicated the presence of only one ester group (likely at C4, as the ester group at C3 is typically first susceptible to hydrolysis, followed by the more sterically hindered $\mathrm{C} 5$ ester). Further investigation showed that modifying the solvent mixture to $\mathrm{THF} / \mathrm{DMF} / \mathrm{MeOH}$ at $40{ }^{\circ} \mathrm{C}$ for $8 \mathrm{~h}$ resulted in full conversion of model substrate $\mathbf{1 0 0}$ to the alkene $\mathbf{5 7}$ (68\%), and very pleasingly these conditions also led to successful generation of 6,7-dideoxysqualestatin $\mathrm{H} 5$ trimethyl ester 72, in $45 \%$ yield (Scheme 34 ).

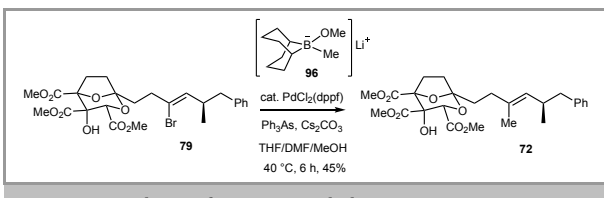

Scheme 34 Synthesis of DDSQ trimethyl ester $\mathbf{7 2}$

With trimethyl ester $\mathbf{7 2}$ in hand, TBAF was initially utilised in an attempt to achieve a formal synthesis of DDSQ, by selectively hydrolysing the C3 ester to give the known DDSQ dimethyl ester $\mathbf{1 4 2}^{39}$ (vide infra, Scheme 45). However, under TBAF conditions, trimethyl ester $\mathbf{7 2}$ decomposed within $30 \mathrm{~min}$ at r.t.; whereas at $0{ }^{\circ} \mathrm{C}$ for less than $10 \mathrm{~min},{ }^{1} \mathrm{H}$ NMR analysis of the crude mixture indicated epimerisation at C3.10 Finally, global hydrolysis using anhydrous $\mathrm{KOH}$ from freshly sublimed $t$ - $\mathrm{BuOK}^{40}$ was attempted. Reaction at $-10^{\circ} \mathrm{C}$ and then gradual warming to $110^{\circ} \mathrm{C}$, at last gave DDSQ (2), following an acidic wash $\left(0.1 \mathrm{~N} \mathrm{HCl}\right.$ at $\left.0{ }^{\circ} \mathrm{C}\right)$ and $\mathrm{MeOH} /$ hexane extraction, in 78\% yield (Scheme 35 ). ${ }^{26}$

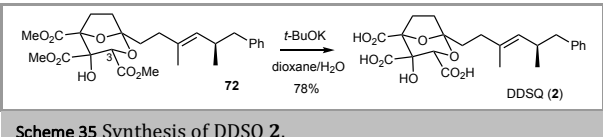

Scheme 35 Synthesis of DDSQ 2 . 
6 An Alternative Strategy to DDSQ: by Cross-Electrophile Coupling

Partly in parallel with the bromide approach above, an alternative strategy for the total synthesis of DDSQ (2) was pursued by Tanzeel Arif and subsequently Younes FeghehHassanpour; this involved a different cross-coupling strategy for direct delivery of unsaturated side-chain $\mathbf{1 0 1}$ to the halidesubstituted post-rearrangement core $\mathbf{1 0 2}$ (Schemes 24 and 36). ${ }^{41}$ The approach aimed to avoid the unwanted reactivity of the alkene moiety in the side-chain during the rearrangement step $(\mathbf{1 0 3} \rightarrow \mathbf{1 0 2})$, and also to shorten the synthesis by attaching the side-chain later in the synthesis. In another key step, the carbonyl ylide precursor, diazoketone 104, was envisaged to be generated from unsaturated hydrazone 105 through sequential chemoselective alkene ozonolysis and hydrazone to diazo transformation. Hydrazone 105 was expected to be accessible by applying our earlier tartrate alkylation approach (Scheme 15), with iodide 106.

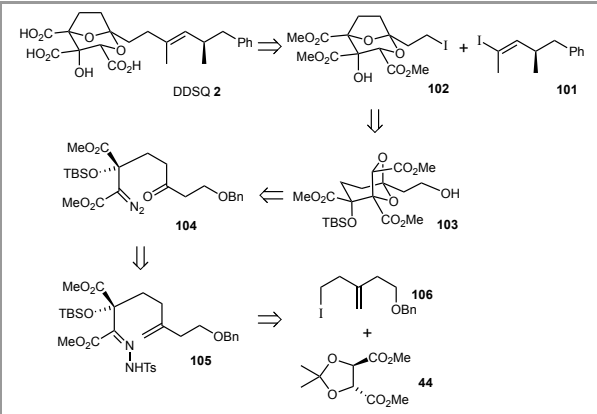

Scheme 36 Retrosynthesis involving side-chain introduction by a cross-coupling strategy

A key feature in this proposed chemistry was selective ozonolysis of an alkene to generate a ketone in the presence of hydrazone functionality. Before committing to this strategy, a model study was designed to establish the stability of a hydrazone moiety towards ozone (Scheme 37). Hydrazone 111, which structurally resembles hydrazone $\mathbf{1 0 5}$ (Scheme 36), was prepared in four steps from commercially available methyl pyruvate (107) and ethyl diazoacetate (108). After silylation, $\alpha$ diazoester 109 was subjected to ozonolysis at $-15{ }^{\circ} \mathrm{C}$ and subsequent hydrazone formation to give hydrazone 111 (75\% from 109). Next, an equimolar solution of hydrazone 111 and alkene 112 (which mimics the alkene portion of unsaturated hydrazone 105) was exposed to ozone $\left(-78{ }^{\circ} \mathrm{C}\right)$ for $\sim 5 \mathrm{~min}$, followed by $\mathrm{Me}_{2} \mathrm{~S}$ as reductant. A mixture of the desired ketone 113 and, importantly, recovered hydrazone $\mathbf{1 1 1}$ was obtained.

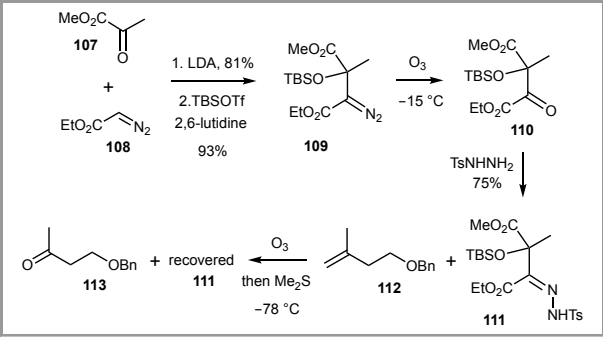

Scheme 37 Synthesis and tolerance to ozonolysis of hydrazone 111

For the preparation of the halide-substituted core 102 ( $c f$, Scheme 36), unsaturated iodide $\mathbf{1 0 6}$ for tartrate alkylation was first prepared starting with hydroxymethylene homologation of the dianion from readily available alcohol 114 (Scheme 38), to produce symmetrical diol $(61 \%, 115$ : TBS $=\mathrm{H})$. Utilising $\mathrm{Ag}_{2} \mathrm{O}$, mono-benzyl protection of the diol (115; TBS $=\mathrm{H})$ took place to give benzyl ether 116. Alternatively, for economic and practical reasons, benzyl ether 116 was prepared starting with TBSetherification to yield the corresponding silyl ether (98\%). Refluxing silyl ether with paraformaldehyde and stoichiometric $\mathrm{Me}_{2} \mathrm{AlCl}$ gave the ene-derived homoallylic alcohol 115. Benzylation of the latter with $\mathrm{BnBr}$ in the presence of $\mathrm{NaH}$ gave benzyl ether 116, after desilylation. Iodination of benzyl ether 116 with $\mathrm{I}_{2}$ in the presence of imidazole and $\mathrm{PPh}_{3}$ gave iodide 106 in quantitative yield (Scheme 38).

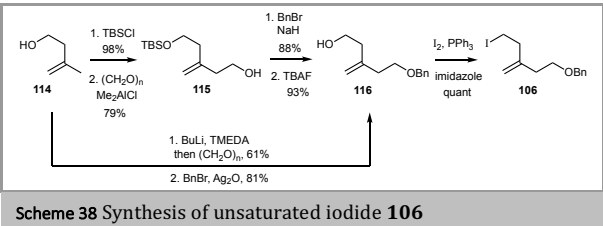

Alkylation of tartrate acetonide $\mathbf{4 4}$ with iodide $\mathbf{1 0 6}$ gave the desired alkylated tartrate $\mathbf{1 1 7}$ along with minor quantities of the elimination-derived diene $\mathbf{1 1 8}$ (Scheme 39). Hydroxylation using MoOPh followed by hydrolysis/silyl protection gave $\alpha$ ketoester 119

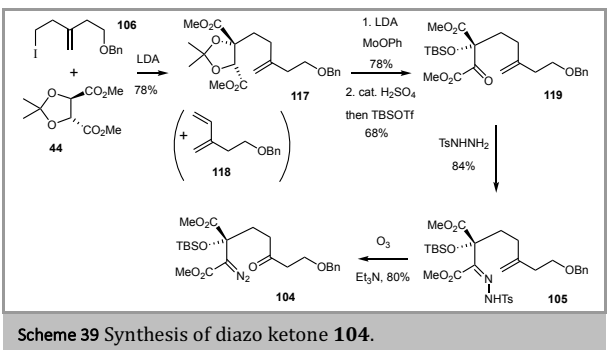

Unfortunately, application of the $-78^{\circ} \mathrm{C}$ ozonolysis conditions from Scheme 37 to hydrazone $\mathbf{1 0 5}$ derived from $\alpha$-ketoester 
119 did not lead to successful isolation of the expected keto hydrazone. Replacement of $\mathrm{Me}_{2} \mathrm{~S}$ by $\mathrm{Et}_{3} \mathrm{~N}$ did, however conveniently generate diazoketone 104 (Scheme 39)! The $\mathrm{Et}_{3} \mathrm{~N}$ plays a dual role, as both base in anionic cycloreversion of the intermediate ozonide ${ }^{42}$ and in the elimination of sulfinate in the Bamford-Stevens step (the latter seen previously in Schemes 10, 15 and 21).

In order to further explore the ozonolysis of unsaturated tosylhydrazones as a direct approach to diazocarbonyl compounds, several other unsaturated tosylhydrazones $\mathbf{1 2 0}$ were designed to examine their reactivity with $\mathrm{O}_{3}$ (at $-78{ }^{\circ} \mathrm{C}$ ), followed by hydrazone decomposition with Et ${ }_{3} \mathrm{~N}$ (Scheme 40). ${ }^{43}$ We found that this chemistry is viable to $\alpha$-diazo- $\varepsilon$-ketoester 121, while an $\alpha$-diazo- $\delta$-ketoester was not observed under the same conditions and instead only keto hydrazone $\mathbf{1 2 2}$ was isolated; switching from $\mathrm{Et}_{3} \mathrm{~N}$ to DBU as a stronger base led to the 2-pyrazoline 123 (41\%). Interestingly, terminal alkene hydrazones $120(\mathrm{R}=\mathrm{H})$ provide a route to cyclic systems $(\mathbf{1 2 4}$ and 125) rather than to diazoaldehydes; the latter being presumed unstable intermediates.

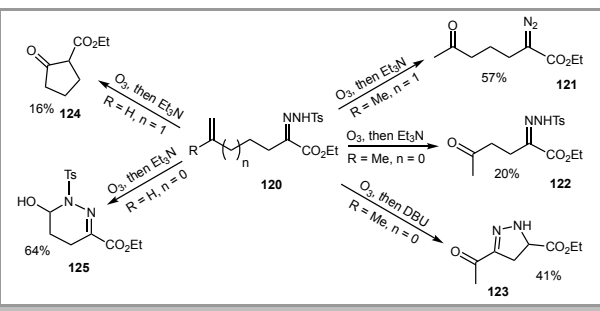

Scheme 40 Ozonolysis followed by base treatment of various unsaturated tosylhydrazones $\mathbf{1 2 0}$

Cyclic $\alpha, \beta$-unsaturated hydrazones 127-129, derived from ketones 126, underwent ozonolytic ring-cleavage and BamfordStevens reaction to give 2,5- and 2,6-diazoketones (130-132, Scheme 41).

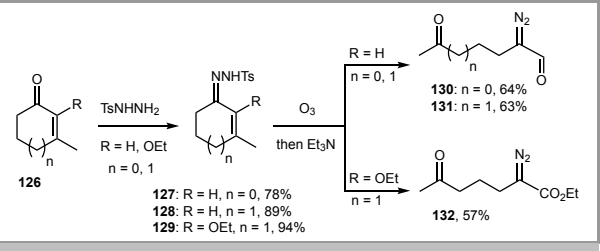

\section{Scheme 41 Synthesis of 2,5- and 2,6-diazoketones 130-132}

Returning to the DDSQ synthesis, Rh-catalysed cycloaddition of diazoketone 104, debenzylation and acid-catalysed rearrangement of alcohol 103 gave a 40:60 ratio of the rearranged core 134 and cycloadduct 133 (Scheme 42). In this case the rearranged core was unfavoured, but in the model system (Scheme 8), and the bromide route (Scheme 29), the rearranged core was favoured $(66: 34,33: 32)$ and $(60: 40$, 79:90), respectively. These results indicate the equilibrium position is sensitive to variation in the C-1 chain. Nevertheless, the unrearranged diol 133 could be recycled (68\% of rearranged core $\mathbf{1 3 4}$ after 2 recycles). Iodination of the rearranged core $\mathbf{1 3 4}$ gave the iodo-substituted core $\mathbf{1 0 2}$.

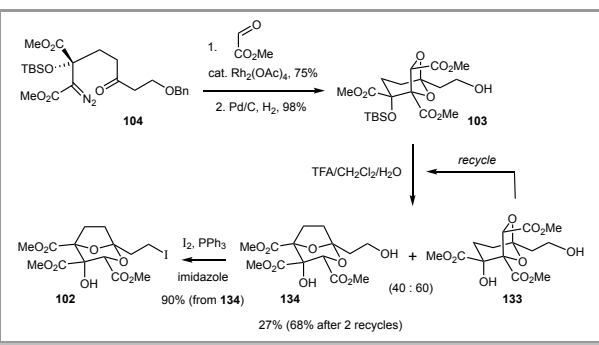

\section{Scheme 42 Synthesis of iodo-substituted core 102}

The synthesis of enantiopure alkenyl iodide partner $\mathbf{1 0 1}$ for the iodo-substituted core $\mathbf{1 0 2}$ started with Corey-Fuchs olefination of $(R)$-aldehyde $\mathbf{5 9}$ to give dibromoalkene $\mathbf{1 3 5}$ in $89 \%$ yield (Scheme 43). Subsequent internal alkyne 136 formation (97\%) was followed by hydrozirconation using excess Schwartz's reagent $\left(\mathrm{Cp}_{2} \mathrm{ZrHCl}\right)$. Subsequent trapping of the intermediate alkenylzirconium with $\mathrm{I}_{2}$ gave the $E$-alkenyl iodide $\mathbf{1 0 1}$ in good overall yield (74\%) from alkyne $\mathbf{1 3 6}$ and with complete control of regio and stereoselectivity.

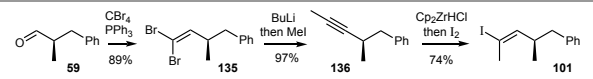

\section{Scheme 43 Synthesis of alkenyl iodide 101}

With the key intermediates $\mathbf{1 0 1}$ and $\mathbf{1 0 2}$ in hand, we were now in a position to address their union. Considerable experimentation was carried out on the $\mathrm{Csp}^{3}-\mathrm{Csp}^{2}$ crosscoupling of alkenyl iodide $\mathbf{1 0 1}$ and iodide core $\mathbf{1 0 2}$ (or their corresponding bromides), but with no or limited success. Unexpected thermal instability (decomposing above ambient) of iodide core $\mathbf{1 0 2}$ was encountered. At the same time as we were studying this issue, Weix and co-workers reported an improved method for cross-coupling of alkyl halides with alkenyl bromides under $\mathrm{Ni}$ catalysis in DMPU with Mn and TMSCl at room temperature. ${ }^{44}$ On applying this method with iodide $\mathbf{1 3 7}$ and $\mathrm{rac}-\mathbf{1 0 1}$ (as a model study, Scheme 44 , bpy $=2,2^{\prime}$ bipyridine), we were pleased to find after reaction optimisation (concentration, ratio of reactants) that entirely $E$-alkene $\mathbf{1 3 9}$ was obtained in $65 \%$ yield. However, a significant erosion in stereochemical integrity was observed when the same conditions were used with the real coupling partners 101 and 102 (vide infra 141: 3:1, E/Z, Scheme 45). A slightly more hindered model alkyl iodide 138, as a closer mimic of the oxygenated core 102, was used for further optimisation (Scheme 44). Changing the reaction solvent to DMF instead of DMPU gave alkene $\mathbf{1 4 0}$ in $86 \%$ yield with excellent $E: Z$ selectivity ( $\sim 17: 1)$. When 2 equiv of alkyl iodide $\mathbf{1 3 8}$ was used, the selectivity ratio improved to $\sim 20: 1 \mathrm{E:Z}$, in $88 \%$ yield. 


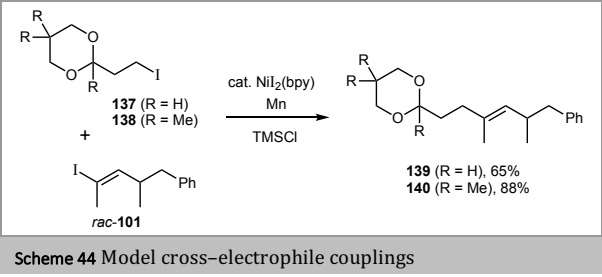

Following the optimised conditions (using DMF as a solvent), stereoretentive Ni-catalysed $\mathrm{Csp}^{3}-\mathrm{Csp}^{2}$ cross-electrophile coupling between iodide core $\mathbf{1 0 2}$ and iodide side-chain 101 proceeded smoothly to give the TMS triesters DDSQ 141 with exclusive $E$-stereochemistry in $66 \%$ yield (Scheme 45). Pleasingly, in this case ( $c f$, trimethyl ester $\mathbf{7 2}$ discussion before Scheme 35) desilylation of $\mathbf{1 4 1}$ with TBAF was accompanied by hydrolysis of the less hindered C-3 ester to afford the known diester DDSQ 142.39 Subsequent saponification of the more hindered methyl esters at C4 and C5 gave DDSQ (2), with this synthesis being completed before the bromide approach (Section 5.2).

$$
\text { Scheme } 45 \text { Cross-coupling and hydrolysis to DDSQ } 2
$$

7 Alkene Ozonolysis in the Presence of Diazo Functionality: Accessing $\alpha$-Ketoester Intermediates

One of the key features of our DDSQ syntheses was the stereoselective alkylation of dimethyl tartrate acetonide (44) with alkyl iodides to access the $\alpha$-diazoesters 143 (Scheme 46). In principle, a more concise approach to such cycloaddition precursors 143 could proceed by aldol reaction between a diazoacetate anion 146 and a suitable $\alpha$-ketoester 145 (Scheme 46), eventually in an asymmetric manner. In such a strategy to DDSQ, the alkene moiety (in 144) would be required to be subsequently converted to a ketone by chemoselective ozonolysis in the presence of diazo functionality.

$$
\text { Scheme } 46 \text { An alternative strategy to diazoketone } \mathbf{1 4 3}
$$

One potential issue with the above alternative route (Schem 46) was that the $\alpha$-diazoester functionality could engage in intramolecular cycloaddition with the electron-rich alkene to form a bicyclic pyrazoline. Indeed, the simpler unsaturated hydrazone $147(\mathrm{R}=\mathrm{H})$ underwent $\mathrm{Et}_{3} \mathrm{~N}$-induced diazo formation in $\mathrm{CH}_{2} \mathrm{Cl}_{2}$ at room temperature to form 1-pyrazoline 148 in $92 \%$ yield (Scheme 47). However, intramolecular cycloaddition was minimised with the 2,2-dialkyl-substituted terminal alkene $147(\mathrm{R}=\mathrm{Me})$, to give diazo alkene 149 as the major product $(52 \%)$, along with only small amounts of the corresponding bicyclic pyrazoline (91:9, respectively).

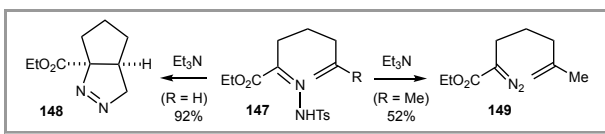

Scheme 47 Reactivity of unsaturated hydrazones 147 with Et $3 \mathrm{~N}$

Another concern was the stability of the diazo group under ozonolysis conditions ( $c f, \alpha$-diazo to $\alpha$-keto ester transformation at $-15{ }^{\circ} \mathrm{C}, \mathbf{1 0 9} \rightarrow \mathbf{1 1 0}$ Scheme 37 ). While it was considered that electron-rich alkenes should react faster than diazo functionality $\alpha$ - to an electron-withdrawing group (eg, ester), a model study was carried out to check the robustness of the $\alpha$ diazo ester moiety towards ozone at $-78{ }^{\circ} \mathrm{C}$ (Scheme 48). An equimolar solution of model diazoester 150 (that resembles the diazo pattern in 144 (Scheme 46)) and alkene 151 (which mimics the alkene portion of 144) was subjected to ozone treatment $\left(-78{ }^{\circ} \mathrm{C}\right.$ in $\mathrm{CH}_{2} \mathrm{Cl}_{2}$ for $\sim 5$ min then, following $\mathrm{N}_{2}$ sparging, addition of $\mathrm{Et}_{3} \mathrm{~N}$ ); a clean crude mixture of the desired ketone $\mathbf{1 5 2}$ and recovered diazoester $\mathbf{1 5 0}$ was obtained.

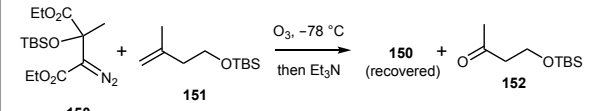

Scheme 48 Stability of $\alpha$-diazoester 150 towards ozone at $-78^{\circ} \mathrm{C}$

In order to test the generality of this chemistry, more readily accessible $\beta$-substituted (or keto) $\alpha$-diazocarbonyl compounds 153a-e (Scheme 49) were prepared to determine if steric and/or electronic factors bias the stability of the diazo moiety to ozonolysis. $\beta$-Substituted $\alpha$-diazoesters $153 \mathbf{a}$-c were reactive at $-78{ }^{\circ} \mathrm{C}$ being converted to the corresponding ketones 154a-c after addition of $\mathrm{Et}_{3} \mathrm{~N}$. In contrast, $\beta$-keto- $\alpha$-diazoesters 153d,e were found to be stable to ozone. The presence of electronwithdrawing functionality at the $\beta$-position of the $\alpha$-diazoester clearly further reduces the reactivity of the diazo group towards ozone; $\beta$-keto- $\alpha$-diazoester 153d was stable to ozone even under warming the reaction mixture to $-15{ }^{\circ} \mathrm{C}$ for $1 \mathrm{~h}$ (alkene 151 converts to ketone 152 within $5 \mathrm{~min}$ at $-78^{\circ} \mathrm{C}$ ). 


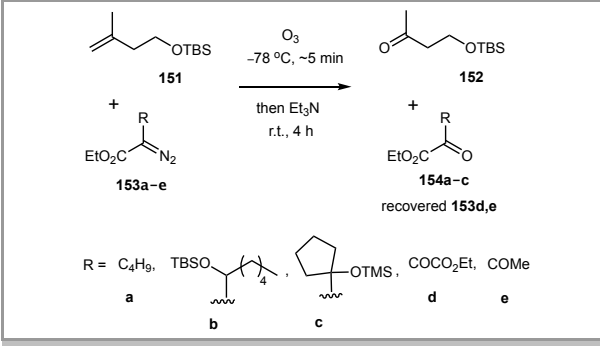

Scheme 49 Tolerance of various $\beta$-substituted ( $\beta$-keto) $\alpha$ diazoesters towards ozone

Encouraged by the above observations, we examined the aldol/ozonolysis strategy (Scheme 46). Initially, $\alpha$-ketoester (145, Scheme 50) was synthesised through Grignard reaction of bromide 155 with oxalate (156), but in only $11 \%$ yield. Alternatively, halogen-lithium exchange of iodide 106 using $t$ BuLi improved the yield to $37 \%$. Next, $\alpha$-ketoester 145 was reacted with lithiated ethyl diazoacetate 108 to give diazoalcohol $157(78 \%)$, and notably with no undesired intramolecular cycloaddition.

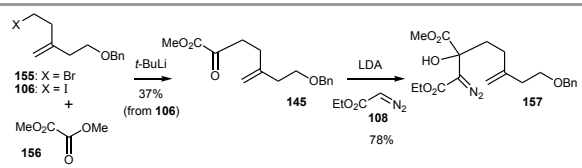

Scheme 50 Synthesis of diazo-alcohol 157

At this stage, we proceeded to protect the $\mathrm{OH}$ group, since otherwise it would likely undergo problematic $\gamma$-lactolisation with the ketone subsequently generated on ozonolysis. On a similar motif, $\gamma$-lactolisation of diazo-alcoho 158 was observed by Carol Villalonga-Barber in one of our very early model studies (Scheme 51). ${ }^{45}$

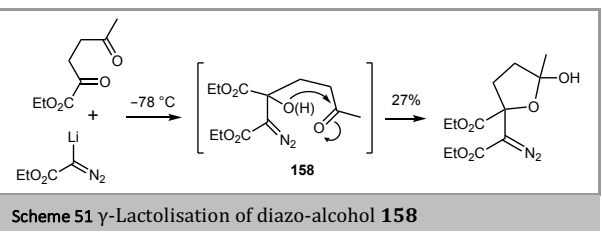

Interestingly, when diazo-alcohol $\mathbf{1 5 7}$ was treated with TBSOTf in the presence of 2,6-lutidine, a mixture of desired TBS ether 159a along with cycloadduct 160a (as a single diastereomer) was obtained (159a:160a, 1:2; Scheme 52). The partial formation of cycloadduct 160a on silylation was attributed to a Thorpe-Ingold effect, from the bulky silyl group. Indeed, on minimising the steric effect by using a less-hindered trimethylsilyl group, the ratio of silyl ether $159 \mathrm{~b}$ to cycloadduct 160b became 4:3 in favour of the desired non-cyclic product. Lastly, the silyl ethers 159a and 159b were subjected to ozonolysis at $-78^{\circ} \mathrm{C}$ in $\mathrm{CH}_{2} \mathrm{Cl}_{2}$ for $\sim 5 \mathrm{~min}$; subsequent addition of $\mathrm{Et}_{3} \mathrm{~N}$ led to the desired diazo-ketones 161a and 161b (58\% and $61 \%$ yields, respectively). ${ }^{46}$

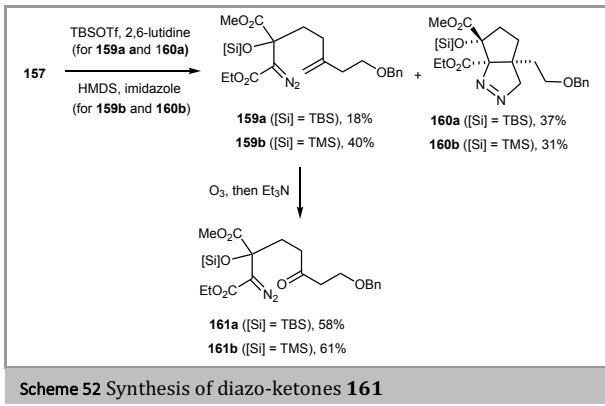

The above chemistry shows that the aldol/ozonolysis strategy, which hinges on chemoselective ozonolysis of unsaturated $\alpha$ diazoesters, is a viable route to $\alpha$-diazo- $\varepsilon$-ketoesters. Further adaptation of this strategy towards DDSQ will require development of a challenging asymmetric aldol addition between an alkyl diazoacetate and ketoesters. ${ }^{47}$

\section{Summary}

"The toughest question to ask in synthetic organic chemistry after the work is done is: what have you learned?" 48 For the research described in this Account, three learning highlights are: (i) new ways to assemble diazo ketones from direct ozonolytic conversion of unsaturated hydrazones and diazo compounds, (ii) prevention of electrophilic attack (protonation/Friedel-Crafts cyclisation) of an alkene by using a temporary vinylic bromine substituent; (iii) highly stereoselective Wittig-Schlosser-type access to $E$ - (rather than the originally anticipated $Z$-) alkenyl bromides and iodides. Our interest in diazocarbonyl-derived carbonyl ylide cycloadditions initiated in this project also led to the development of catalytic asymmetric variants, but that is another story. ${ }^{49,50}$

\section{Funding Information}

For studentship funding we thank the EPSRC, the University of Oxford, the Higher Education Commission of Pakistan, the Sultanate of Oman and the Higher Committee for Education Development in Iraq.

\section{Acknowledgment}

The brevity with which the work detailed in this Account is described cannot do justice to the amount of effort that actually went into developing the chemistry. For that reason, D.M.H. would like to thank all the dedicated co-workers who have been involved with him in this area contributions.

\section{References}

(1) Permanent address: University of Kufa, Najaf Governorate, Iraa

(2) Hodgson, D. M.; Bray, C. D.; Humphreys, P. G. Synlett 2006, 1

(3) Hoffmann, R. Angew. Chem., Int. Ed. Engl. 1988, 27, 1593.

(4) Padwa, A. Acc. Chem. Res. 1991, 24, 22.

(5) Sidebottom, P. J.; Highcock, R. M.; Lane, S. J.; Procopiou, P. A.; Watson, N. S. J. Antibiot. 1992, 45, 648

(6) Wilson, K. E.; Burk, R. M.; Biftu, T.; Ball, R. G.; Hoogsteen, K. J. Org. Chem. 1992, 57, 7151. 
(7) Blows, W. M.; Foster, G.; Lane, S. J.; Noble, D.; Piercey, J. E.; Sidebottom, P. J; Webb, G. J. Antibiot. 1994, 47, 740

(a) Nadin A 1622. (b) Armstrong, A.; Blench, T. J. Tetrahedron, 2002, 58, 9321.

9) Hodgson, D. M.; Bailey, J. M.; Harrison, T. Tetrahedron Lett. 1996, $37,4623$.

(10) Nicolaou, K. C.; Yue, E. W.; la Greca, S.; Nadin, A.; Yang, Z.; Leresche, J. E.; Tsuri, T.; Naniwa, Y.; De Riccardis, F. Chem. Eur. J. 1995, 1, 467 Armstrong, A.; Barsanti, P. A. Synlett 1995, 903.

(12) Hodgson, D. M.; Bailey, J. M.; Villalonga-Barber, C.; Drew, M. G. B.; Harrison, T. J. Chem. Soc,, Perkin Trans. 1 2000, 3432.

(13) Kataoka, O.; Kitagaki, S.; Watanabe, N.; Kobayashi, I; Nakamura, S. Shiro, M.: Hashimoto, S. Tetrahedron Lett. 1998, 39, 2371.

(14) Hodgson, D. M.; Villalonga-Barber, C. Tetrahedron Lett. 2000, 41 5597.

(15) Hodgson, D. M.; Villalonga-Barber, C.; Goodman, J. M.; Pellegrinet, S. C. Org. Biomol. Chem. 2010, 8, 3975.

(16) Evans, D. A.; Barrow, J. C.; Leighton, J. L.; Robichaud, A. J.; Sefkow, M. J. Am. Chem. Soc. 1994, 116, 12111.

(17) Ohno, M. Top. Heterocycl. Chem. 2006, 6, 1

(18) Sintim, H. O.: Valade, A.; Harling D. C.: Hodgson, D. M. Tetrahedron 2019, 75, 130747.

(19) Naef, R.Seebach, D. Angew. Chem, Int Ed Engl. 1981, 20,1030. (20) Seebach, D.; Aebi, J. D.; Gander-Coquoz, M.; Naef, R. Helv. Chim. Acta

(21) Sintim, H. O.; Al Mamari, H. H.; Almohseni, H. A. A.; FeghehHassanpour, Y.; Hodgson, D. M. Beilstein J. Org. Chem. 2019, 15, 1194.

(22) Vedejs, E.; Larsen, S. Org. Synth. 1990, Coll. Vol. 7, 277.

(23) Morita, H.; Arisaka, M.; Yoshida, N.; Kobayashi, J. Tetrahedron 2000 56, 2929.

(24) Sintim, H. O. D Phil Thesis; University of Oxford: UK, 2002

(25) Soai, K.: Oyamada, H. Synthesis 1984, 605

(26) Almohseni, H. A. A.; Mamari, H. H. A.; Valade, A.; Sintim, H. O;

Almohseni, H. A. A.; Mamari, H. H. A.; Valade,
Hodgson, D. M. Chem. Commun. 2018, 54, 5354.

(27) Boeckman, R. K.; Ko, S. S. J. Am. Chem. Soc. 1980, 102, 7146.

(28) Smith, A. B.; Beauchamp, T. J.; LaMarche, M. J.; Kaufman, M. D.; Qiu, Y.; Arimoto, H.; Jones, D. R.; Kobayashi, K. J. Am. Chem. Soc. 2000, 122,8654

(29) Al-Mamari, H. H. D Phil Thesis; University of Oxford: UK, 2005.

(30) Barma, D. K.; Kundu, A.; Zhang, H.; Mioskowski, C.; Falck, J. R. J. Am Chem Soc. 2003, 125, 3218.

\section{Biosketches}

(31) Schlosser, M.; Christmann, F. K.; Piskala, A.; Coffinet, D. Synthesis 1971, 29.

Arif, T. D Phil Thesis; University of Oxford: UK, 2012.

(33) Hodgson, D. M.; Arif, T. J.Am. Chem. Soc. 2008, 130, 16500

Hodgson, D. M.; Arif, T. Chem. Commun. 2011, 47, 2685

Hodgson, D. M.; Arif, T. Chem. Commun. 2011, 47,268
Hodgson, D. M.; Arif, T. Org. Lett. 2010, 12, 4204

(35) Hodgson, D. M.; Arif, T. Org. Lett. 2010, 12, 4204. 9228

(37) Müller, T.; Göhl, M.; Lusebrink, I.; Dettner, K.; Seifert, K. Eur. J. Org. Chem. 2012, 2323

(38) Fürstner, A.; Seidel, G. Tetrahedron 1995, 51,11165.

(39) Naito, S.; Escobar, M.; Kym, P. R.; Liras, S.; Martin, S. F. J. Org. Chem. 2002, 67, 4200

(40) Gassman, P. G.; Schenk, W. N. J. Org. Chem. 1977, 42, 918

(41) Fegheh-Hassanpour, Y.; Arif, T.; Sintim, H. O.; Al Mamari, H. H.; Hodgson, D. M. Org. Lett. 2017, 19, 3540.

(42) Hon, Y.-S.; Lin, S.-W.; Lu, L.; Chen, Y.-J. Tetrahedron 1995, 51, 5019

(43) Fegheh-Hassanpour, Y.; Ebrahim, F.; Arif, T.; Sintim, H. O.; Claridge, T. D. W.; Amin, N. T.; Hodgson, D. M. Org. Biomol. Chem. 2018, 16, 3876.

(44) Johnson, K. A.; Biswas, S.; Weix, D. J. Chem. Eur. J. 2016, 22, 7399.

(45) Villonga Barber, C. D Phil Thesis University of $0 x$ ford UK, 2001.

(46) Almohseni, A. A. H.; Fegheh-Hassanpour, Y.; Arif, T.; Hodgson, D. M.
Synthesis 2019, 51, 4231 .

(47) (a) Wang, F; Liu, X;; Zhang, Y.; Lin, L.; Feng, X.Chem. Commun. 2009, 7297. (b) Yamashita, Y.; Yasukawa, T; Yoo, W.J.; Kitanosono, T.; Kobayashi, S. Chem. Soc. Rev. 2018, 47, 4388.

(48) Gilbert Stork, quoted in: Seeman, J. I. Angew. Chem. Int. Ed. 2012, $51,3012$.

(49) Hodgson, D. M.; Stupple, P. A.; Johnstone, C. Tetrahedron Lett. 1997 38,6471 .

(50) Hodgson, D. M.; Labande, A. H.; Muthusamy, S. Org. React. 2013, 80,

Formatted: Font: Italic
Formatted: Font: Bold
Formatted: Font: Italic

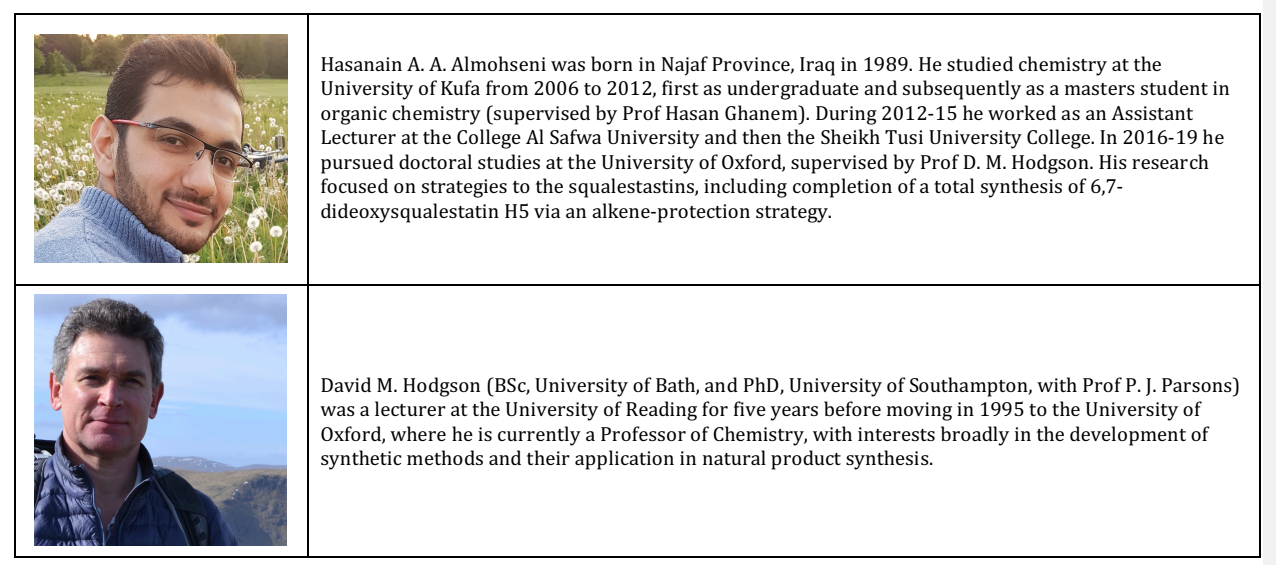

Template for SYNTHESIS (c) Thieme Stuttgart · New York 2020-11-05 